\title{
Lise Öğrencilerinin Kıș Sporlarına Yönelik Farkındalık Düzeylerinin İncelenmesi
}

\author{
Dr. Öğr. Üyesi Yusuf Er ${ }^{1}$ \\ Arş. Gör. Abdullah Çuhadar ${ }^{2 *}$ \\ Doç. Dr. Mehmet Demirel ${ }^{3}$
}

Geliş tarihi: 04.12.2019

Kabul tarihi: 11.02.2020

\section{Atıf bilgisi:}

IBAD Sosyal Bilimler Dergisi

Sayı: $7 \quad$ Sayfa: 136-143

Yıl: 2020 Dönem: Yaz

This article was checked by Turnitin Similartiy Index $24 \%$

Bu makalede araștırma ve yayın etiğine uyulmuş̧tur.

${ }^{1}$ Karamanoğlu Mehmetbey Üniversitesi, Türkiye, $\quad$ err yusuf@hotmail.com ORCID ID: 0000-0001-8441-4283

${ }^{2}$ Karamanoğlu Mehmetbey Üniversitesi, Türkiye,

abdullahcuhadar42@hotmail.com

ORCID ID: 0000-0001-6942-4475

${ }^{3}$ Necmettin Erbakan Üniversitesi, Türkiye, mehmetdemirel78@gmail.com ORCID ID: 0000-0003-1454-022X

\section{*Sorumlu Yazar}

\section{ÖZ}

Çalışmanın amacı lise öğrencilerinin kış sporlarına yönelik farkındalık düzeylerinin farklı değişkenlere göre incelemektir. Çalışmanın Örneklem grubu uygun örnekleme yöntem ile belirlenmiş ve gönüllülük esasına dayanan Ağrı ilindeki lise öğrencilerinden belirlenmiştir. Çalışmada 200 kadın (\%50.0) ve 200 erkek (\%50.0) olmak üzere toplam 400 lise öğrencisi katılımcı olarak yer almıştır. Çalışmaya ilişkin verilerin istatistiksel analizinde demografik verilerin yüzde ve frekanslarına bakılmış, verilerin dağılımını belirlemek için basıklık ile çarpıklık değerleri kontrol edilmiş; bunun sonucunda da parametrik testlerden $t$ testi ve anova analiz yöntemleri kullanılmıştır. Sonuç olarak lise öğrencilerinin cinsiyet, baba mesleği, aile gelir durumu ve spor yapma sıklığı değişkenkenlerine göre kış sporlarına yönelik farkındalık düzeyleri tüm alt boyutlarında anlamlı farklılıklar tespit edilmiştir.

Anahtar Kelimeler: Kış Sporları, Farkındalık, Lise Öğrencileri 


\author{
Assist. Prof. Dr. Yusuf Er ${ }^{1}$ \\ Res. Assist. Abdullah Çuhadar ${ }^{2 *}$ \\ Assoc. Prof. Dr. Mehmet Demirel ${ }^{3}$
}

First received: 04.12.2019

Accepted: 11.02 .2020

\title{
Citation:
}

IBAD Journal of Social Sciences

Issue: 7

Pages: 136-143

Year: 2020

Session: Summer

This article was checked by Turnitin. Similartiy Index 24\%

${ }^{1}$ Karamanoğlu Mehmetbey Universtiy, Turkey, err yusuf@hotmail.com

ORCID ID: 0000-0001-8441-4283

2Karamanoğlu Mehmetbey Universtiy, Turkey, abdullahcuhadar42@hotmail.com ORCID ID: 0000-0001-6942-4475

${ }^{3}$ Necmettin Erbakan Universtiy, Turkey, mehmetdemirel78@gmail.com

ORCID ID: 0000-0003-1454-022X

\footnotetext{
* Corresponding Author
}

\begin{abstract}
The aim of the study is to determine the level of awareness of high school learning for winter sports according to different variables. Sample group; The appropriate sampling method was designed on a voluntary basis from high school students in Ağrı. A total of 400 high school students, 200 females (50.0\%) and 200 males $(50.0 \%)$, participated in the study.I $n$ the statistical analysis of the data related to the study, the percentages and frequencies of the demographic data were examined and the kurtosis and skewness values were checked to determine the distribution of the data; consequently the parametric $t$ test and ANOVA test methods were used.As a result, significant differences were found in all sub-dimensions of high-school students' awareness of winter sports according to the variables of gender, father's profession, family income and frequency of sports.
\end{abstract}

Keywords: Winter Sports, Awareness, High School Students 


\section{GİRISŞ}

Spor; "bireyin toplumsal uyumu, ruh ve beden sağlığı, yarışma kazanma öğelerini içermekte, kişiliğin oluşumu ve gelişimi yönünden eğitimcilerin önerdikleri bir disiplin, kitlelerin çok beğendiği bir seyir, enerjiyi biçimlendirmek ve dengeli, mücadeleci bir anlayış uyandırmak için yöneticilerin kullandıkları bir yöntem, insana haz ve doyum veren bir oyun güdüsünün gelișkin kurallara bağlanmıș anlatım şeklidir" (Kat, 2009). Spor, insanların yalnızca fiziksel gelişimini sağlamak amacında değildir. Aynı zamanda insanların hayatları boyunca öğrenmelerine ve katılımcı olmaya dair çeşitli bilgiler edinmelerine katkıda bulunur. Bu bağlamda spor, yalnızca sağlıklı ve mutlu olmanın, doyuma ulaşmanın bir yolu değil, aynı zamanda da bir eğitim aracıdır (Ergül ve ark., 2016). Bu özelliklerinden dolayı çağımızda spor çok yönlü, çok faydalı, çok amaçlı ve çok çeşitli boyutlar kazanmış ve evrenselleşmiştir (Yetim, 2005; Aydın, 2007, s.203-210). Sportif faaliyetlerin tarihin çok eski zamanlarından beri bireye ve topluma birçok alanda önemli katkılarının olduğu bilinmektedir (Gratton ve Henry, 2001; Orçanlı ve ark., s.2). Bireylerin mutlu olmak, tatmin olmak, doyuma ulaşmak adına yaptıkları sportif etkinlikler kapsamındaki rekreatif etkinlikler bireylerin yaşantılarının her döneminde önem arz etmektedir (Soyer ve ark., 2017). İçinde barındırdığı bu nitelikleriyle uluslar üstü bir konuma gelen sportif faaliyetlerin, sadece insanların dış dünyaya karşı kendilerini ifade ediş biçimi olmaktan çıktığını, ülkelerin kültürlerarası ilişkilerinde stratejik önem taşıyan etkili taktik araçlar haline geldiğini söylemek mümkündür (Yıldız ve Bitirim, 2005; Boyac1, 2013, s.1).

Bireyin kendisine, çevresine ve evrene ilişkin bilinçlilik düzeyinin ve bilinç alanının genişlemesi, farkına varma yoluyla gerçekleşir. Herhangi bir uyarıcının fark edilebilmesi için öncelikle o uyarıcının, belirli bir eşiği aşabilecek güçte olması ve duyu organlarına ulaşması gereklidir. Ancak duyu organlarına ulaşan herşeyin farkına varılamaz. Yeni bir uyarıcının fark edelebilmesi için; yeni uyarıcıyı mevcut zihinsel şemalarla bağdaştırmaya, tanımlamaya; yeni uyarıcı karşısında heyecan duymaya (duygusal yaşantı geçirmeye); yeni uyarıcı ile iletişime girme isteği duymaya ihtiyaç vardır (Dökmen, 2002; Eski, 2010, s.3).

Farkındalık, bireylerin bilişsel duyuşsal ve psikomotor olarak ilgi ve yetenekleri doğrultusunda yapmak istedikleri etkinliklere yönelmeleri ve başarılı olmaları yolunda gereksinim duyulan önemli bir başlangıç noktası olarak karşımıza çıkmaktadır. Bireylerin herhangi bir konuyla ilgili farkındalık düzeyi düşük ise o durumla ilgili bir yaşantı içine girmesi beklenilemez (Eski, 2010; Ünal, 2017, s.1).

Spor aktivitelerinin gelişmesi ve toplumda yaygınlaşması, spor tesislerin varlığıyla mümkündür (Atasoy ve Kurter, 2005; Orçanlı ve ark., 2018, s.2). Kış sporları yaygınlığı her geçen gün artan spor faaliyetlerindendir. $\mathrm{Bu}$ sporları içeren turnuva ve olimpiyatlar yaygın olarak yapılmakta ve televizyonlarda canlı yayınlanarak tüm dünyaya ulaşmaktadır. Bu durum yaygınlığının daha da artacağı anlamına gelmektedir. Bu spor branşlarını sadece profesyonel sporcular değil, amatörler de yapmaktadır (Tetik ve ark., 2002, s.42-55). Sporun etkinliklerinin bütünleştirici ve sosyalleştirici unsurlarından hareketle; bireyin sportif ve rekreatif etkinliklere katılımının ve farkındalığının sosyal toplumun bir gerekliliği olduğunu göz önüne sermektedir (Ekinci ve ark., 2015, s.71-78).

Kış sporlarındaki sporcu ve izleyici katılımındaki artış, kış turizm merkezlerine olan talep ve basın yayın organlarında yer alan haberler kış sporlarına ve kış sporları merkezlerine duyulan ilgiyi göstermektedir. Uluslararası alanda olimpik kış sporları ile ilgili yedi farklı federasyonun faaliyet göstermesi kış sporlarındaki gelişmeyi ortaya koymaktadır (Eski, 2010, s.4). Bu doğrultuda yapılan bu çalışma da lise öğrencilerinin kış sporlarına yönelik farkındalık düzeylerinin farklı değişkenlere göre incelenmesi amaçlanmiştır.

\section{YÖNTEM}

2.1. Araştırma Modeli: Betimsel tarama modelli bir çalışma niteliğinde olan çalışmada seçkisiz olmayan örnekleme yöntemlerinden uygun örnekleme yöntemi belirlenmiştir. Bu araştırmada çalışma grubunun seçiminde seçkisiz olmayan, uygun örnekleme yöntemi benimsenmiştir. Büyüköztürk ve ark. (2008), uygun örnekleme yöntemini para ve işgücü kaybını önlemeyi temel amaç edinen bir yöntem olarak tanımlamışır. 
2.2. Evren ve Örneklem: Ağrı ilindeki lise öğrencilerinden gönüllük esasına dayalı olarak, uygun örnekleme yöntemi kullanılarak seçilmiş olan ve örneklem grubunu; 200 kadın ve 200 erkek olmak üzere toplam 400 lise öğrencisi oluşturmaktadır.

2.3. Veri Toplama Aracı: Verilerin toplanmasında Eski (2010) tarafından oluşturulmuş olan "Kış Sporları Farkındalık Ölçeği" kullanılmıştır. 5'li Likert tipi olan bu ölçek, "Kişisel Bilgiler ve Farkındalık" düzeyini ölçen 2 bölümden oluşmaktadır. Eski (2010) tarafindan geliştirilen "Kış Sporları Farkındalık Ölçeği" "hiç", "az", "orta", "çok" ve "tam" olmak üzere 5 likert'li, 35 madde ve 3 alt boyuttan oluşan "Kış sporlarına yönelik farkındalık ölçeği" kullanılmıştır. Ölçekteki ilk alt boyut olan bilişsel boyut, bireyin beden eğitimi ve spor öğrenme alanlarında yer alan kavram, ilke, kural, taktik ve stratejik bilgileri edinme yolları, üzerinde işlemler ve genellemeler yapabilme gibi zihinsel süreçlerinin farkına varması ile ilgilidir ve 13 maddeden oluşmaktadır. Ölçeğin ikinci alt boyutu olan duyuşsal boyut, bireyin beden eğitimi ve spor alanları ile ilgili geçmiş yaşantılardan elde edilen tecrübeler neticesinde zihinde oluşan ilgi, istek, tutum, kaygı, tepki, endişe, korku gibi düşünce ve hislerinin farkına varması ile ilgilidir ve 13 maddeden oluşmaktadır. Üçüncü alt boyut olan psikomotor boyut, bilişsel ve duyuşsal farkındalığın bireyi daha somut davranışla, doğal ve sosyal çevrenin etkisi ile katılıma yöneltmesi, eyleme geçirmesi ile ilgilidir ve 9 maddeden oluşmaktadır.

2.4. Verilerin Toplanması ve Analizi: Verilerin istatistiksel analizinde demografik verilerin yüzde ve frekanslarına bakılmış, verilerin dağılımını belirlemek için basıklık ile çarpıklık değerleri kontrol edilmiş; bunun sonucunda da parametrik testlerden $t$ testi ve anova analiz yöntemleri kullanılmıştır $(\alpha=$ 0.05). Jondeau ve Rockinger (2003)' e göre alt boyutların çarpıklık ve basıklık katsayılarının +3 ile -3 arasında değiştiğinde bu alt boyutlarında normal dağılım parametrelerine uygun şartlar taşıdığını belirtmiştir. Ölçek alt boyutlarının Cronbach Alpha iç tutarlılık katsayısı .67 ile .75 arasında değişmekte olup, toplam Cronbach Alpha iç tutarlılık katsayısı ise .79 olarak bulunmuştur.

\section{BULGULAR}

Bu bölümde lise öğrencilerine uygulanmış olan ölçek ve demografik veriler sonucunda elde edilen bulgular yer almaktadır.

Tablo 1: Katılımcıların Kişisel Bilgilerinin Yüzdelik Değerleri

\begin{tabular}{|c|c|c|c|}
\hline & Değişkenler & $\mathbf{f}$ & $\%$ \\
\hline \multirow[t]{3}{*}{ Cinsiyet } & Kadın & 200 & 50 \\
\hline & Erkek & 200 & 50 \\
\hline & Toplam & 400 & 100 \\
\hline \multirow[t]{6}{*}{ Baba Mesleği } & Memur & 40 & 10,0 \\
\hline & Emekli & 106 & 26,5 \\
\hline & Serbest Meslek & 145 & 36,3 \\
\hline & Çalışmıyor & 50 & 12,5 \\
\hline & Diğer & 59 & 14,8 \\
\hline & Toplam & 400 & 100 \\
\hline \multirow{6}{*}{ Aile Gelir Durumu } & $0-800 \mathrm{TL}$ & 71 & 17,8 \\
\hline & $801-1600 \mathrm{TL}$ & 73 & 18,3 \\
\hline & $1601-2400 \mathrm{TL}$ & 116 & 29,0 \\
\hline & $2401-3200 \mathrm{TL}$ & 73 & 18,3 \\
\hline & 3201 TL ve Üzeri & 67 & 16,8 \\
\hline & Toplam & 400 & 100 \\
\hline \multirow[t]{6}{*}{ Spor Yapma Sıklığı } & Hiç & 105 & 26,3 \\
\hline & Nadiren & 60 & 15,0 \\
\hline & Bazen & 132 & 33,0 \\
\hline & Genellikle & 73 & 18,3 \\
\hline & Siklıkla & 30 & 7,5 \\
\hline & Toplam & 400 & 100 \\
\hline
\end{tabular}


Araştırma kapsamındaki katılımcıların demografik bilgilerinin dağılımı incelendiğinde \%50'sinin $(n=200)$ erkek, \%50'sinin de $(n=200)$ kadın olduğu, baba mesleği değișkenine göre \%36.3'ünün serbest meslek olduğu, \%29.0'nın aile gelir durumu 1601-2400 tl arasında olduğu, spor yapma sıklığı değişkenine göre ise \%33.0'ı bazen olarak ifade etmişlerdir.

Tablo 2. Cinsiyete Göre KışS Sporlarına Yönelik Farkındalık Düzeyi Ölçeği Alt Boyutları

\begin{tabular}{lccccc}
\hline Alt Boyutlar & Değişken & Ort. & Ss & t & p \\
\hline Bilişsel Boyut & Kadın & 2,65 &, 711 & $-2,67$ & \multirow{2}{*}{, 008} \\
& Erkek & 2,85 &, 731 & & \\
\hline Duyuşsal Boyut & Kadın & 2,87 &, 796 & $-5,62$ & \multirow{2}{*}{, 000} \\
& Erkek & 3,33 &, 834 & & \\
\hline Psikomotor Boyut & Kadın & 2,80 &, 775 & $-2,60$ & \multirow{2}{*}{, 010} \\
& Erkek & 3,00 &, 783 & & \\
\hline
\end{tabular}

Cinsiyet değişkenine göre Kış Sporlarına Yönelik Farkındalık Düzeyi Ölçeği (KSYFD) alt boyutları arasında yapılan T Testi sonuçlarına göre KSFYD alt boyutları arasında cinsiyet faktöründe anlamlı farklılık olduğu belirlenmiştir $(p<0.05)$. Anlamlı farklılığın ortalamalar dikkate alındığında "Erkek" katılımcılardan kaynaklandığı belirlenmiştir.

Tablo 3. Kış Sporlarına Yönelik Farkındalık Düzeyi Ölçeğinin Baba Mesleğine Göre Puan Dağıllımları

\begin{tabular}{|c|c|c|c|c|c|}
\hline Alt Boyutlar & Değişken & Ort. & Ss & $\mathbf{F}$ & $\mathbf{p}$ \\
\hline \multirow[t]{5}{*}{ Bilişsel Boyut } & Memur & 3,20 & ,675 & \multirow{5}{*}{10,96} & \multirow{5}{*}{.000} \\
\hline & Emekli & 2,51 & ,711 & & \\
\hline & Serbest M. & 2,74 & ,598 & & \\
\hline & Çalışmıyor & 2,58 & 825 & & \\
\hline & Diğer & 3,05 & ,762 & & \\
\hline \multirow[t]{5}{*}{ Duyuşsal Boyut } & Memur & 3,54 & ,751 & \multirow{5}{*}{9,51} & \multirow{5}{*}{, 000} \\
\hline & Emekli & 2,73 & 864 & & \\
\hline & Serbest M. & 3,14 & ,744 & & \\
\hline & Çalışmıyor & 3,12 & ,788 & & \\
\hline & Diğer & 3,33 & 928 & & \\
\hline \multirow[t]{5}{*}{ Psikomotor Boyut } & Memur & 3,08 & ,701 & \multirow{5}{*}{2,68} & \multirow{5}{*}{, 031} \\
\hline & Emekli & 2,72 & 850 & & \\
\hline & Serbest M. & 2,94 & ,680 & & \\
\hline & Çalışmıyor & 2,85 & ,949 & & \\
\hline & Diğer & 3,05 & ,760 & & \\
\hline
\end{tabular}

Baba Mesleği değişkenine göre KSYFD alt boyutları arasında yapılan ANOVA Testi sonuçlarına göre tüm alt boyutlarda anlamlı farklılık olduğu belirlenmiştir $(p<0.05)$. Anlamlı farklılığın ortalamalara bakıldığında baba meslek durumu "Memur" olan katılımcılardan kaynaklandığı belirlenmiştir.

Tablo 4. Gelir Düzeyi Değişkenine Göre Kış Sporlarına Yönelik Farkındalık Düzeyi Ölçeği Alt Boyutları Ölçek Puanlarının Dağılımı

\begin{tabular}{lccccc}
\hline Alt Boyutlar & Değişken & Ort. & Ss & F & p \\
\hline Bilişsel Boyut & $0-800$ & 2,62 &, 673 & & \\
& $801-1600$ & 2,60 &, 708 & & .017 \\
& $1601-2400$ & 2,80 &, 652 & 3,06 & \\
\cline { 2 - 4 } & $2401-3200$ & 2,74 &, 731 & & \\
\cline { 2 - 4 } & 3201 ve Üst & 2,97 &, 862 & & \multirow{2}{*}{000} \\
\cline { 2 - 4 } Duyuşsal Boyut & $0-800$ & 2,74 &, 750 & & \\
& $801-1600$ & 2,85 &, 760 & 8,46 & \\
\cline { 2 - 4 } & $1601-2400$ & 3,34 &, 783 & & \\
\hline
\end{tabular}




\begin{tabular}{|c|c|c|c|c|c|}
\hline & $2401-3200$ & 3,24 &, 881 & & \\
\hline & 3201 ve Üst & 3,19 & ,919 & & \\
\hline \multirow[t]{5}{*}{ Psikomotor Boyut } & $0-800$ & 2,67 & ,756 & \multirow{5}{*}{4,28} & \multirow{5}{*}{, 002} \\
\hline & $801-1600$ & 2,74 & ,784 & & \\
\hline & $1601-2400$ & 3,04 & ,763 & & \\
\hline & $2401-3200$ & 3,08 & ,756 & & \\
\hline & 3201 ve Üst & 2,88 & 809 & & \\
\hline
\end{tabular}

Gelir düzeyi değişkenine göre KSYFD alt boyutlarına göre yapılan ANOVA Testi sonuçlarına göre tüm alt boyutlarda anlamlı bir farklılık olduğu saptanmıştır $(\mathrm{p}<0.05)$.

Tablo 5. Spor Yapma Sıklığı Değiş̧kenine Göre Kış Sporlarına Yönelik Farkındalık Düzeyi Ölçeği Alt Boyutların Puanlarının Dağllımı

\begin{tabular}{|c|c|c|c|c|c|}
\hline Alt Boyutlar & Değişken & Ort. & Ss & $\mathbf{F}$ & $\mathbf{p}$ \\
\hline \multirow[t]{5}{*}{ Bilişsel Boyut } & Hiç & 2,44 & 668 & \multirow{5}{*}{14,51} & \multirow{5}{*}{.000} \\
\hline & Nadiren & 2,68 & ,741 & & \\
\hline & Bazen & 2,75 & ,586 & & \\
\hline & Genellikle & 3,00 & ,687 & & \\
\hline & Siklıkla & 3,38 & ,943 & & \\
\hline \multirow[t]{5}{*}{ Duyuşsal Boyut } & Hiç & 2,65 & ,792 & \multirow{5}{*}{15,28} & \multirow{5}{*}{, 000} \\
\hline & Nadiren & 3,22 & ,784 & & \\
\hline & Bazen & 3,09 & ,719 & & \\
\hline & Genellikle & 3,45 & ,852 & & \\
\hline & Siklıkla & 3,60 & ,943 & & \\
\hline \multirow[t]{5}{*}{ Psikomotor Boyut } & Hiç & 2,53 & ,722 & \multirow{5}{*}{10,13} & \multirow{5}{*}{,000 } \\
\hline & Nadiren & 3,02 & ,863 & & \\
\hline & Bazen & 2,94 & ,760 & & \\
\hline & Genellikle & 3,13 & ,743 & & \\
\hline & S1klıkla & 3,24 &, 571 & & \\
\hline
\end{tabular}

Spor sapma sıklığı değişkenine göre KSYFD alt boyutları arasında yapılan ANOVA Testi sonuçlarına göre tüm alt boyutlarda anlamlı farklılık olduğu belirlenmiş̧tir $(\mathrm{p}<0.05)$.

\section{TARTIŞMA ve SONUÇ}

$\mathrm{Bu}$ araştırmanın amacı lise öğrencilerinin kış sporlarına yönelik farkındalık düzeylerinin; cinsiyet, baba mesleği, aile gelir durumu ve spor yapma sıklığı değişkenlerine göre farklılık gösterip göstermediğini incelemektir.

Araştırmada elde edilen veriler doğrultusunda cinsiyet değişkenine göre incelendiği zaman ; öğrencilerin kış sporlarına yönelik farkındalık düzeyleri alt boyutlarında erkek katılımcılar lehine anlamlı farklılık olduğu belirlenmiştir. Literatürdeki benzer çalışmalar incelendiği zaman sonuçların araştırmamızla benzerlik gösterdiği görülmektedir. Ünal (2017), ortaöğretim öğrencileri yaptıkları çalışma da cinsiyet

değişkenine göre kış sporları farkındalık düzeyi ölçeği alt boyutlarında erkek öğrenciler lehine anlamlı farklılık olduğunu rapor etmiştir. Bir başka araştırmada Eski (2010) tarafından ortaöğretim öğrencilerine yapılan çalışmada kış sporlarına yönelik farkındalık düzeyi alt boyutlarında cinsiyet değişkenine göre erkekler lehine anlamlı farklılık gösterdiğini tespit etmiştir. Bu sonuçlardan hareketle cinsiyet farklılığına göre farkındalık oranının değiştiğini, erkek öğrencilerin farkındalık düzeylerinin kız öğrencilerden yüksek olduğunu göstermektedir.

Katılımcıların baba meslekleri ve kış sporlarına yönelik farkındalık düzeyleri arasındaki ilişki ele alındığı zaman tüm alt boyutlarda anlamlı farklılık olduğu tespit edilmiştir. Oluşan bu anlamlı farklılığın memur katılımcılardan kaynaklandığı belirlenmiştir. Eski (2010) tarafından yapılan araştırmada ortaöğretim öğrencilerinin baba mesleği değişkenine göre kış sporlarına yönelik farkındalık düzeyleri alt boyutları 
arasında anlamlı farklılık olduğunu ve babaları memur olan öğrencilerin farkındalık düzeylerinin anlamlı şekilde yüksek olduğunu rapor etmiştir.

Araştırmaya katılan lise öğrencilerinin aile gelir düzeyi değişkenine göre incelendiği zaman kış sporlarına yönelik farkındalık düzeyleri tüm alt boyutlarında anlamlı farklılık olduğu belirlenmiştir. Eski (2010) yapmış olduğu çalışmada öğrencilerin aile gelir düzeyi değişkeni ve kış sporlarına yönelik farkındalık düzeyi alt boyutları arasında anlamlı farklılık olduğunu tespit ederken öğrencilerin farkındalık ortalamalarının ailenin ortalama aylık geliriyle birlikte anlamlı şekilde yükseldiğini belirtmiştir.

Araştırmada spor yapma sıklığı değişkenine göre ortaya çıkan farklılıklar değerlendirildiği zaman kış sporlarına yönelik farkındalık düzeyleri alt boyutlarında tüm alt boyutlarda anlamlı farklılık olduğu belirlenmiștir. Ünal (2017), ortaöğretim öğrencileri yaptıkları çalışmada öğrencilerin spor yapma durumları ile kış sporlarına yönelik farkındalık düzeyi alt boyutları arasında anlamlı farklı1ık olduğunu tespit ederken oluşan bu anlamlı farklılığın spor yapan bireylerden kaynaklandığını ifade etmiştir.

\section{KAYNAKÇA}

Atasoy, B. \& Kurter, F.Ö. (2005). Küreselleşme ve spor. Uludağ Üniversitesi Eğitim Fakültesi Dergisi, $X \operatorname{VIII}(1), 11-22$.

Aydın, A. D. (2007). Sarıkamış’ın kış sporları turizmi potansiyeli açısından değerlendirilmesi. Süleyman Demirel Üniversitesi Sosyal Bilimler Enstitüsü Dergisi, (6), 203210.

Boyacı, M. (2013). 2011 Erzurum üniversiteler arası kış oyunlarının toplumsal algısı. Yayımlanmamış yüksek lisans tezi, Mehmet Akif Ersoy Üniversitesi Eğitim Bilimleri Enstitüsü, Burdur.

Büyüköztürk, Ş., Çakmak, K., E., Akgün, E., Ö., Karadeniz, Ş., \& Demirci, F. (2008). Bilimsel Araştırma Yöntemleri. Ankara: Pegem Akademi.

Dökmen, Ü. (2002). Yarına kim kalacak? Evrenle uyumlaşma sürecinde varolmak gelişmek uzlaşmak. İstanbul: Kişisel Gelişim Dizisi Sistem Yayıncılık.

Ekinci, N. E., Demirel, M., Demirel, D. H., \& Işık, U. (2015). Lise öğrencilerinin yalnızlık algılarının rekreasyonel etkinliklere katılımları ve bireysel değişkenlere göre incelenmesi. Sportif Bakış: Spor ve Eğitim Bilimleri Dergisi, 2(2), 71-78.

Ergül, M., A., Tınaz, C., Ertaç, M. (2016). Lise Öğrencilerinin spora yönelik farkındalık düzeylerine etki eden faktörlerin incelenmesi: Tenis branşı örneği. Hacettepe Spor Bilimleri Dergisi, 27(2), 69 83.

Eski, T. (2010). Ortaöğretim öğrencilerinin kıs sporlarına yönelik farkındalık düzeylerinin değerlendirilmesi (Kastamonu İli örneği). Yayımlanmamış doktora tezi, Gazi Üniversitesi Eğitim Bilimleri Enstitüsü, Beden Eğitimi ve Spor Öğretmenliği Anabilim Dalı, Ankara.

Gratton, C. \& Henry, I.P. (2001). Sport in the city, the role of sport in economic and social regeneration. London: Routledge.

Jondeau, E., \& Rockinger, M. (2003). Conditional volatility, skewness, and kurtosis: Existence, persistence, and comovements. Journal of Economic dynamics and Control, 27(10), 1699-1737.

Kat, H. (2009). Bireysel sporcularla takım sporcularının stres düzeyleri ve problem çözme becerilerinin karşılaştırılması. Yayımlanmamış yüksek lisans tezi, Erciyes Üniversitesi Sağlık Bilimleri Enstitüsü, Kayseri.

Orçanlı, K. (2018). Kış sporları merkezlerine farkındalık algısının oluşmasını etkileyen faktörlerin belirlenmesi (Erzurum ili örneği). Sosyal Bilimler Araşstırma Dergisi, 7(3), 1-19. 
Soyer, F., Yıldız, N. O., Demirel, D. H., Serdar, E., Demirel, M., Ayhan, C., \& Demirhan, O. (2017). Üniversite öğrencilerinin rekreatif etkinliklere katılımlarına engel teşkil eden faktörler ile katılımcıların yaşam doyumları arasındaki ilişkinin incelenmesi. Journal of Human Sciences, 14(2), 2035-2046.

Tetik, O., Aydog., T. Demirel, AH., Atay, ÖA., \& Doral MN. (2002). Kış sporlarında spor yaralanmalar1. Spor Bilimleri Dergisi Hacettepe Journal of Sport Sciences, 13(4), 42-55.

Ünal, E. (2017). Ortaokul 7. ve 8. sinıf öğrencilerinin kıs sporlarına yönelik farkındalık düzeylerinin incelenmesi (Erzurum ili örneği). Yayımlanmamış yüksek lisans tezi, Atatürk Üniversitesi, Eğitim Bilimleri Enstitüsü, Beden Eğitimi ve Spor Öğretmenliği Anabilim Dalı, Erzurum.

Yetim, A. Azmi. (2005). Sosyoloji ve spor. İstanbul: Morpa Kültür yayınları.

Yıldız, E., \& Bitirim, S. (2005). Kültürlerarası iletişim açısından UNIVERSIADE (Dünya üniversite oyunları) İzmir 2005. İstanbul İletişim Fakültesi Dergisi, (32), 165-186. 